\title{
Research on the construction ventilation scheme of concealed subway station
}

\author{
WANG Chen ${ }^{1}$, ZHAO Jian-hui ${ }^{1 *}$, LI Ze-hua ${ }^{2}$, CHEN Jia-mei ${ }^{1}$, LIU Pan-xue ${ }^{1}$ \\ ${ }^{1}$ College of Energy Engineering. Xi'an University Of Science And Technology. Xi`an.710054; \\ ${ }^{2}$ College of Architecture and Civil Engineering. Xi`an University Of Science And Technology. Xi`an.710054
}

\begin{abstract}
With the development of underground transportation, in order to reduce the impact on the surrounding environment and traffic, Hejiaying subway island station adopts the concealed excavation method. During the construction process, considering the construction method, tunnel layout, ventilation requirements, and the construction working face as a multi-conductor cave, more stringent requirements are put forward for the construction ventilation of the tunnel. Through the combination of theoretical calculation and numerical simulation, a ventilation method suitable for the actual construction conditions at the site was developed. After applying the scheme to practice, the feasibility of the scheme was verified through the determination of field data, and the improvement of the construction environment for tunnel personnel was achieved, which has certain reference value for similar projects.
\end{abstract}

\section{INTRODUCTION}

As underground structures, subways are mostly characterized by large cross-sections, proximity to buildings (structures) and concealed excavation construction. However, the concealed excavation method has the disadvantages of relatively closed operating environment and the generated particulate matter is not easily discharged, which will lead to a poor underground construction environment, so it is necessary to study the distribution of pollutants in the concealed excavation subway stations and the influence of the same part on pollutants. ${ }^{[1][2][3][4]}$

According to the basic principles of tunnel engineering ventilation, the tunnel space layout of Hejiaying station, the size and shape of the tunnel section, the construction method, the configuration and number of construction personnel and equipment, and the construction ventilation requirements, the ventilation equipment to meet the ventilation effect is analyzed, and large diameter air ducts are used as much as possible to reduce energy loss when the headroom allows.

\section{Project Overview}

Hejiaying station is located under the north side of the intersection of South Chang'an Street and Shenhe Second Road in Chang'an District, and is a $13.0 \mathrm{~m}$ platform island station with a three-span double-column underground two-story cast-in-place straight-wall triple-arch structure, laid along Changning Street, with undulating terrain and ground elevation between 466.611 and $479.763 \mathrm{~m}$, and the geomorphological unit is a first-class loess plateau
(Shenhe Plateau) area. According to the construction design, the construction method used for the tunnel is the PBA method.

\section{NUMERICAL SIMULATION OF TUNNEL VENTILATION CONSTRUCTION}

\subsection{Mathematical principles}

The basic principle of Computational Fluid Dynamics is the analysis of a system containing physical phenomena related to fluid flow and heat conduction by means of computer numerical calculations and image display.

This paper is based on the assumption of unsteady flow and incompressible fluid, and uses the momentum, energy, and mass conservation equations and the standard $\mathrm{k}-\varepsilon$ turbulence mathematical model to simulate the variation of air volume and pressure during the mechanical ventilation of Shaft No. 1.

\subsection{Tunnel 3D modeling}

Hejiaying station is excavated by the cavity-pile method, and the main pollution is generated at the palm face, and the overall press-in ventilation is used, so the mechanical ventilation process during tunnel excavation is mainly simulated. The whole project is divided into three shafts excavated in opposite directions at the same time, and the overall model is large and the gridding is difficult to be divided, so the model is simplified and the guide hole with the longest distance in the first shaft is taken as the research object.

\footnotetext{
*Corresponding author: ${ }^{\mathrm{a} z h a o j h @ x u s t . e d u . c n}$

b1366591020@qq.com
} 
The dimensions of the whole station are approximately $230.3 \times 21.9 \times 16.5$, and the length of the guide hole attached to the first shaft is about 80 meters for simulation, and the diameter of the ducts are 1.2 meters for the shaft, 1 meter for the cross passage, 0.8 meters for the guide hole, and 10 meters for the working surface. ICEM software in ANSYS was used to establish the 3D model and mesh division (see Figure 1 below). Considering the calculation efficiency and accuracy requirements, the grid encryption was carried out for the tunnel wall and the corner of the duct wall, and the total number of grids was 3230853, with an average grid quality of 0.857 .

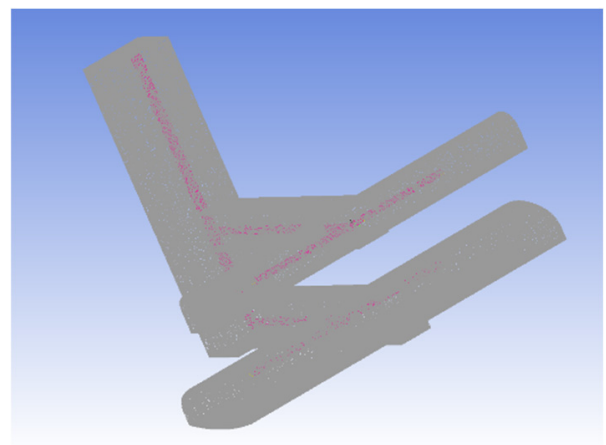

Figure 1: Three-dimensional meshing of the tunnel

\subsection{Boundary Conditions}

The entrance of the shaft outlet duct is the air supply of the ventilation fan, and the air speed is $22.39 \mathrm{~m} / \mathrm{s}$. The air speed is set to $23 \mathrm{~m} / \mathrm{s}$. According to the model established, the wind speed will be sent into the tunnel along the negative direction of $z$-axis, and the speed of $x$ and $y$-axis is zero, assuming uniform wind speed.

Set the air duct outlet as the air supply outlet, the air duct is connected to the outside world, the outlet temperature and pressure is the same as the outside world, the temperature is set to $25^{\circ} \mathrm{C}$, the pressure is $101.325 \mathrm{KPa}$.

The tunnel, palm face and ventilation pipe walls are all standard solids to avoid, assuming no slippage, no friction, and the same temperature and pressure as the atmosphere.

\section{CFD SIMULATION ANALYSIS}

\subsection{Wind speed}

The wind speed of the whole duct in the shaft No. 1 changes, as can be seen from Figure 2, the inlet wind speed is about $22 \mathrm{~m} / \mathrm{s}$ and the outlet wind speed is about $6.09 \mathrm{~m} / \mathrm{s}$. At the beginning, the air has not yet reached the working surface, and at the turn where the shaft meets the cross passage, there is a sudden change in speed due to the effect of wind suction, and the turbulent jet air forms a reverse vortex in the shaft. After continuous ventilation, the air speed in the duct basically tends to stabilize.

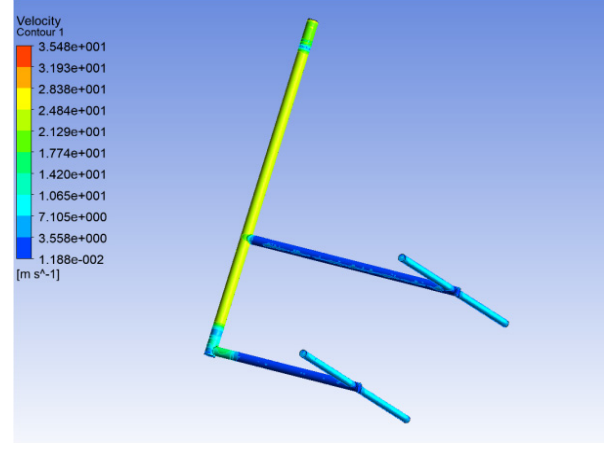

Figure 2: Distribution of wind speed in the duct

\subsection{Pressure}

The pressure change of the whole duct in the shaft No.1, as can be seen from Figure 3, the pressure at the inlet is about $135,786 \mathrm{~Pa}$, and the pressure at the outlet is about $101,026 \mathrm{~Pa}$. At the beginning of ventilation, the maximum wind pressure is at the fan outlet, and the minimum wind pressure is at the bend. The wind pressure is too small. The pressure at the working surface is about $101067 \mathrm{~Pa}$, because the actual process of ventilation produces negligible pressure loss.

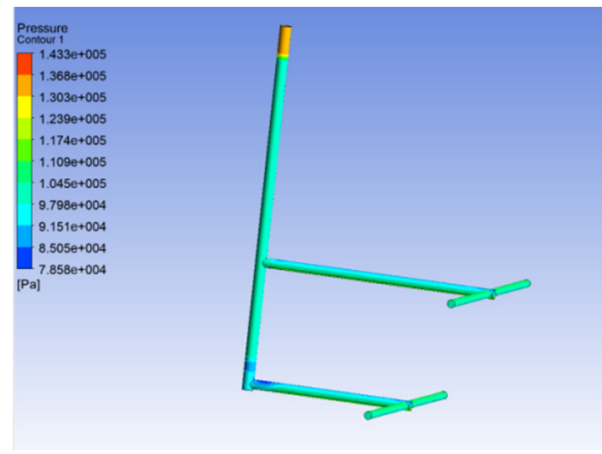

Figure 3: Distribution of partial pressure in the duct

\section{TUNNEL AIR QUALITY MONITORING}

\subsection{Test content and measurement point arrangement}

In order to further verify and improve the ventilation design during tunnel construction and to ensure the health of the construction personnel and the safety of the construction process, the air velocity in the tunnel during construction was tested. By testing the air volume and dust in different parts, we provide a basis for optimizing and improving the ventilation plan.

During the field test, a total of nine sections were taken for measurement, as shown in Figure 4. The test sites were: air duct supply and its surrounding, air duct outlet and its surrounding, near the working surface, tunnel axis section and tunnel cavity entrance, etc. 


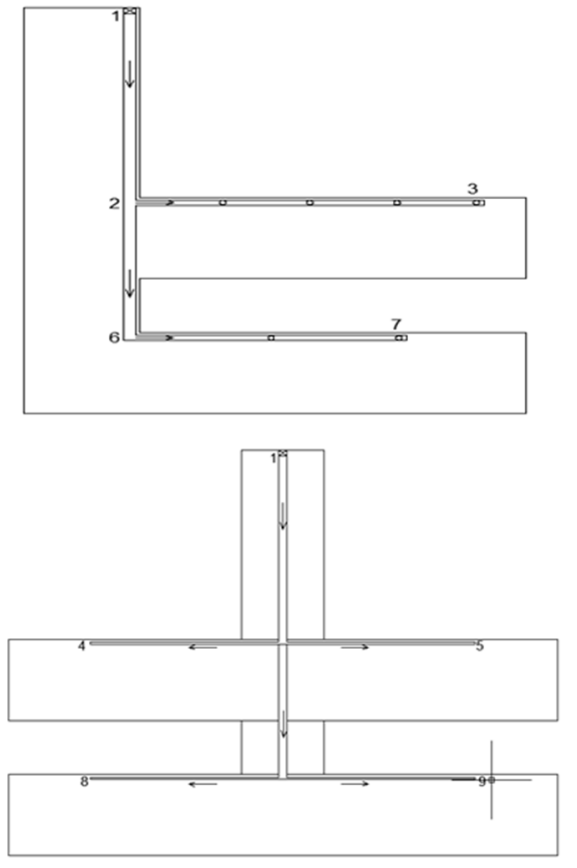

Figure 4: Arrangement of detection points

\subsection{Wind speed test results}

The wind speed test results for each part of the tunnel are shown in Figures 5-6 below.

From the fan outlet to the duct outlet, the wind speed gradually becomes smaller due to the presence of frictional resistance and along-travel resistance.

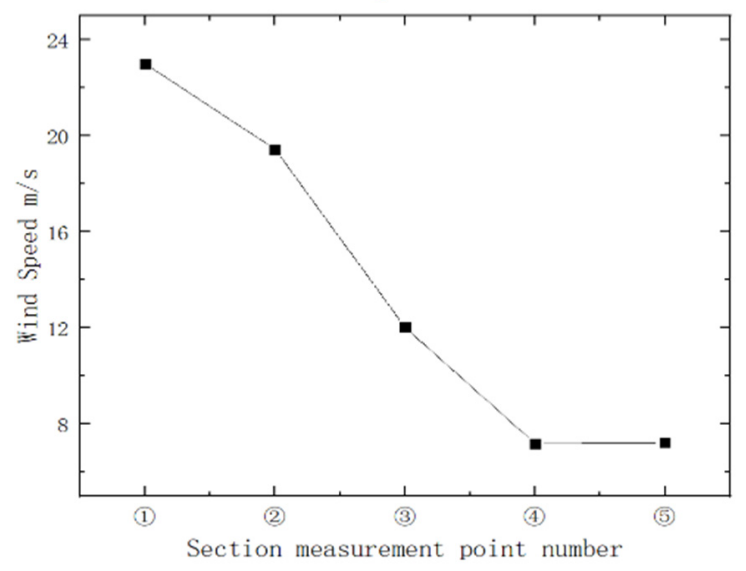

Figure 5: Wind speed distribution in the upper pilot tunnel

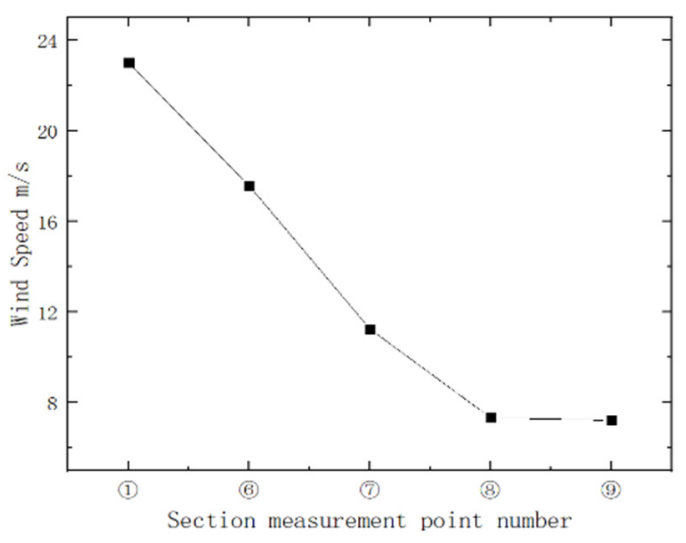

Figure 6: Wind speed distribution in the lower pilot tunnel

\subsection{Dust test results}

During the construction process, the ventilation fan was turned on for dust removal, and the change of dust after $100 \mathrm{~min}$ of ventilation time was tested. As can be seen from Figure 7, although the air quality is poor at the beginning of ventilation, the dust concentration is gradually decreasing throughout the ventilation process, and the air quality can meet the sanitary requirements after ventilation.

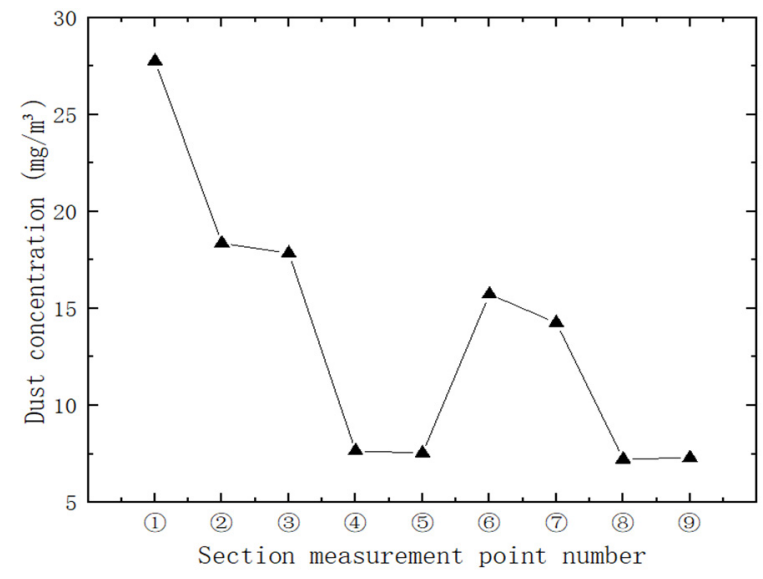

Figure 7: Dust concentration distribution

\section{Conclusion}

In recent years, with the increasing development of subway construction, the cave-pile method has been widely used for its advantages such as being conducive to the protection of groundwater resources and beneficial to the safety of nearby underground structures and surrounding buildings. Combined with the study on the construction ventilation scheme of Hejiaying island subway station, the following conclusions are drawn.

1)Through the actual tunnel construction process, the press-in ventilation method, fan selection and piping arrangement are feasible in the cavity pile construction method, and can meet the requirements of the tunnel construction specifications for air volume and pressure.

2) Combined with the simulation results and field testing data analysis shows that, during the tunnel 
construction process, when the inlet air velocity is $22 \mathrm{~m} / \mathrm{s}$, although there is a sudden change in the duct velocity due to the wind suction effect at the bend, the lowest air velocity at the exit to the working surface is $6.09 \mathrm{~m} / \mathrm{s}$, which is basically consistent with the calculation results, indicating that the ventilation system can effectively meet the ventilation requirements.

3) In the later stage of the study, the monitoring of dust in key construction parts such as palm faces should be strengthened, so as to provide a healthy and good working environment for the tunnel by timely adjustment of air volume changes according to actual changes.

\section{REFERENCES}

1. Zhang Heng. Construction ventilation technology of complex network tunnel group[D]. Southwest Jiaotong University.2013

2. Xia Enhu. Rapid ventilation technology with small section and multiple pilot tunnels in underground excavated subway stations $[\mathrm{J}]$ Shandong Transportation Technology. 2017(01):113-114.

3. Wang Junzhou. Numerical simulation of tunnel construction ventilation based on ANSYS Fluent[J]. Northwest Hydropower. 2018 (03):85-90.
4. Xiaoke Chang,Junrui Chai,Jipeng Luo,et. Tunnel ventilation during construction and diffusion of hazardous gases studied by numerical simulations[J]. Building and Environment,2020,177.

5. GB 50299-1999. Code for construction and acceptance of metro engineering.1999

6. Xie Yongli. Tunnel Engineering[M]. Chongqing University Press.201501.

7. Huang Xianzhou.Chen Shi.Wei Zhiguo et. Mixed Construction Ventilation of Lancang River Super Long Tunnel. [J] Chinese Journal of Underground Space and Engineering. 2020,16(S1):353-359+382.

8. Zhou Jian, Zou Yilun, Xu Wanghao, etc. Ventilation scheme design for the exit section of Micangshan Highway Tunnel[J]. Journal of China \& Foreign Highway. 2020,40(03):199-204.

9. Ma Deping.et.3D numerical simulation of construction ventilation effect for underground chamber group of Xiangjiaba Hydropower Station[J]. Yangtze River. 2011,42(01):29-32+53.

10. ZHANG Hua,CHEN Hao. Design, Implementation and Testing of Ventilation of Extra-long Highway Tunnel[J]. Road Machinery \& Construction Mechanization. 2019,36(12):96-101. 